\title{
Rapid DNT Fluorescent Films Detection with High Sensitivity and Selectivity
}

\author{
Hongwei Ma, Feng Li, Zhaoxia Zhang, Ming Zhang*
}

State Key Laboratory of Supramolecular Structure and Materials, Jilin University, Changchun 130012, P. R. China. Tel: +86-0431-85167507. Fax: +86-0431-85193421.

Keywords: fluorescent sensor; DNT; rapid detection; high sensitivity; high selectivity

\begin{abstract}
In this study, we designed and synthesized two small fluorescent molecules, TCAC and TCA. Their spin-coated films were used as fluorescent sensors for 2, 4-dinitrotoluene (DNT) vapor. Compared with TCAC, which has carbazole units at the end of the hexyl side chains, TCA films exhibited better sensitivity and selectivity to DNT vapor with good reutilization in $30 \mathrm{~s}$. Furthermore, TCA was performed to detect trace DNT by contact mode approach for real-time field and visualized detection with good performances.
\end{abstract}

\section{Introduction}

Detection of trace explosives such as 2, 4, 6-trinitrotoluene (TNT) and 2, 4dinitrotoluene (DNT) is of great significance due to their serious threat to homeland security and public safety [1-3]. So far, the common techniques detected trace explosives mainly include gas chromatography mass spectrometry (GC-MS) [4,5], X-ray imaging [6], ion mobility spectroscopy (IMS) [7], surface-enhanced Raman spectroscopy [8,9], and electrochemical methods $[10,11]$. But these technologies usually exhibit some disadvantages such as high cost, complicated operation and time-consuming. Specially, the poor portability makes these techniques not suitable for the real-time field detection. Compared with these techniques, fluorescence detection shows low cost, good portability, 
high sensitivity and selectivity. Besides that, the fluorescent films could be easily incorporated into a handheld device for the real-time field detection of explosives [12]. Up to date, many fluorescent materials have been used for explosives detection, such as conjugated polymers [13], luminescent metal-organic frameworks [14], bio-inspired materials [15], aggregation induced emission (AIE) materials [16,17], nanomaterials [18] and so on. The main mechanism ascribes to the photoinduced electron transfer (PET) [19]. Based on this mechanism, some fluorescent materials are designed with electron rich groups to enhance the electron donating ability [20]. In addition, the morphology of the sensing films is another key to influence the sensing performances, thus, some designed molecules with "big" units in the backbone or sidechains are designed to achieve the porous films, which benefit the diffusion of the explosives and improve the contact of the sensing materials and the explosives [21].

DNT is toxic and may cause anemia, abnormal liver function, cataract development and skin irritation $[22,23]$. It has been list of stress control pollutants by United States Environmental Protection Agency (US EPA) [24]. The detection of DNT is of great importance and deserved exploring. Firstly, DNT has similar chemical structure with TNT. It is the major impurity and the decomposition product of TNT. The saturated vapor pressure of DNT (411 ppb) is much higher than TNT ( $9.15 \mathrm{ppb})$, thus, the small quantities of DNT that contained in TNT hold the dominating vapor, which can serve as the marker for TNT vapor detection [25]. So rather than attempting to detect low vapor pressure of TNT directly, researchers often focus on detecting DNT vapor [26,27]. Secondly, the selective detection between DNT and TNT is still a challenge, which is due to their similar chemical structure. Finally, the rapid detection of DNT is extremely 
needed for the practical application. As we know, it takes long time for the passengers at airports for security checks, and the working efficiency is urgently needed to be improved through the rapid detection [28]. Thereby, the detection of DNT with high sensitivity and selectivity deserve further exploration, however, less attention are paid to this study.

Herein, we designed and synthesized two fluorescent molecules, TCAC and TCA (Scheme 1), their spin-coated films are used as the fluorescent sensor to DNT. The difference between TCAC and TCA is the sidechains, which might make their spincoated films exhibit distinguishing sensing performance to DNT. And the results show that TCA, which has hexyl as the sidechains, is a rapidly responsive, highly selective and real-time fluorescent sensor to DNT.

\section{Experimental}

\subsection{Materials and methods}

All chemicals and solvents were purchased from commercial sources. Reactions were all conducted under argon atmosphere. ${ }^{1} \mathrm{HNMR}$ spectra were recorded on a Bruker AVANCZ 500 spectrometer at $500 \mathrm{MHz}$, using $\mathrm{CDCl}_{3}$ as the solvent at $298 \mathrm{~K}$, and tetramethylsilane (TMS) as the internal standard. Ultraviolet-visible (UV-vis) absorption spectra were recorded on a model UV-3100 spectrophotometer. Fluorescence spectra were performed using a model RF-5301PC spectrophotometer.

\subsection{Synthesis of TCAC and TCA}

TCAC: ${ }^{1} \mathrm{H}-\mathrm{NMR}\left(500 \mathrm{MHz}, \mathrm{CDCl}_{3}\right): \delta 8.06(\mathrm{t}, 8 \mathrm{H}), \delta 7.95(\mathrm{~m}, 2 \mathrm{H}), \delta 7.83(\mathrm{~m}, 2 \mathrm{H})$, $\delta 7.72(\mathrm{~m}, 4 \mathrm{H}), \delta 7.49(\mathrm{~m}, 1 \mathrm{H}), \delta 7.37(\mathrm{~m}, 16 \mathrm{H}), \delta 7.32(\mathrm{~m}, 4 \mathrm{H}), \delta 7.25(\mathrm{~m}, 4 \mathrm{H}), \delta$ $7.18(\mathrm{~m}, 9 \mathrm{H}), \delta 7.10(\mathrm{~m}, 3 \mathrm{H}), \delta 7.02(\mathrm{~m}, 1 \mathrm{H}), \delta 4.15(\mathrm{~m}, 8 \mathrm{H}), \delta 1.92(\mathrm{~m}, 8 \mathrm{H}), \delta 1.70$ 
$(\mathrm{m}, 8 \mathrm{H}), \delta 1.15(\mathrm{~m}, 16 \mathrm{H}), \delta 0.76(\mathrm{~m}, 8 \mathrm{H}) .{ }^{13} \mathrm{C}-\mathrm{NMR}\left(125 \mathrm{MHz}, \mathrm{CDCl}_{3}\right): \delta$ 130.03, $127.68,127.35,127.04,126.05,125.54,125.02,123.52,120.31,119.92,118.68,108.61$, 42.93, 40.24, 29.69, 28.79, 26.86, 23.74. MALDI-TOF-MS: 1504.8. Calcd. for $\mathrm{C}_{112} \mathrm{H}_{102} \mathrm{~N}_{4}: \mathrm{N}: 3.73 \%$, C: $89.44 \%$, H: $6.84 \%$. Found: N: $3.63 \%$, C: $89.59 \%$, H: $6.97 \%$.

TCA: ${ }^{1} \mathrm{H}-\mathrm{NMR}\left(500 \mathrm{MHz}, \mathrm{CDCl}_{3}\right): \delta 7.98(\mathrm{~d}, 2 \mathrm{H}), 7.91-7.75$ (m, $\left.6 \mathrm{H}\right), 7.54-7.33(\mathrm{~m}$, $14 \mathrm{H}), 2.09-1.98$ (m, $8 \mathrm{H}), 1.20-1.06(\mathrm{~m}, 24 \mathrm{H}), 0.89-0.71$ (m, $20 \mathrm{H}) .{ }^{13} \mathrm{C}$ NMR (126 $\left.\mathrm{MHz}, \mathrm{CDCl}_{3}\right): \delta 150.95,140.79,127.42-126.74,124.99,122.92,119.73,40.49,31.57$, 29.69, 23.91, 22.53, 14.04. MALDI-TOF-MS: 843.31. Calcd. for $\mathrm{C}_{64} \mathrm{H}_{74}: \mathrm{C}: 91.15 \%$, H: $8.85 \%$. Found: C: $91.44 \%$, H: $8.86 \%$.

\subsection{Preparation of Spin-coated films}

The films of TCAC and TCA were fabricated by spin-coated on quartz substrates with a rate of $1500 \mathrm{rpm}$ and a concentration of $0.5 \mathrm{mg} \mathrm{mL}^{-1}$ in THF. Then the films were in vacuum at $45^{\circ} \mathrm{C}$ for $10 \mathrm{~min}$ to remove the residual solvents.

\subsection{Fluorescence detection of explosives vapor}

The explosives powder was put into the quartz cell bottom, then a suitable filter paper was put on the powder to prevent the direct contact between the films and the powder, finally, the quartz cell was sealed. After $60 \mathrm{~min}$, the films were put into the cell. The fluorescence spectra were recorded as a function of exposed time under the excitation light at $360 \mathrm{~nm}$. 
To study the reusability of the spin-coated films, after being exposed to explosives vapor, the films were immersed into methanol for $60 \mathrm{~min}$, and then dried in vacuum oven at $45^{\circ} \mathrm{C}$ for $1 \mathrm{~h}$. The fluorescence emission of films could be recovered.

\section{Results and discussion}

Scheme 1. The synthetic routes of TCAC and TCA.

TCAC and TCA were synthesized through Suzuki reaction according to the previous literatures [1]. Their molecular structures are shown in Scheme 1. As can be seen, TCAC and TCA have the same rigid backbone composed of anthracene and fluorene groups but different sidechains. TCA has four hexyl sidechains, while TCAC has carbazole groups at the end of the hexyl sidechains, which could enhance the donating ability [29]. TCAC and TCA have the same backbone composed of anthracene and fluorene groups. The rigid anthracene groups could not only reduce the $\pi$ stacking of molecules but also create a loose microstructure to benefit the diffusion of explosives vapor and enhance the contact between the sensing materials and explosives. 
The absorption spectrum of TCAC in THF displays main absorption bands located at 294, 308, 332, 346, 360, 379 and $399 \mathrm{~nm}$, respectively (Figure S1). The bands at 294, 332 and $346 \mathrm{~nm}$ are attributed to the transition of the carbazole groups, the band at $308 \mathrm{~nm}$ is attributed to the electronic transition of fluorene groups, and the bands at 360, 379 and $399 \mathrm{~nm}$ are attributed to $\pi-\pi^{*}$ transition of the anthracene group. TCA exhibits similar absorption bands of fluorene and anthracene groups. The PL spectra of TCAC and TCA exhibit the same blue emission located at $435 \mathrm{~nm}$ in THF (Figure 1). However, comparing PL spectra of the films with those in solution, red-shifts of $2 \mathrm{~nm}$ for TCA and $7 \mathrm{~nm}$ for TCAC are observed. The big red-shifts of TCAC might be attributed to the $\pi-\pi$ interaction between the carbazole groups and the rigid backbone of TCAC. This significantly small red-shift of TCA films suggests TCA films have much looser microstructure, which could provide efficient pathway for the diffusion of the explosives vapor.

\section{Figure 1}

Figure 1. PL spectra of TCAC and TCA in solution and as films. The inset: enlarged view of PL spectra.

Further, TCAC and TCA films were used as the fluorescent sensors for explosives. As we know that the false signals often come from similar explosives in the sensing field, and the false signals are related to the lack of selectivity. Therefore, some common explosives were tested firstly shown as Figure 2, including DNT, TNT, Octahydro-1, 3, 5, 7-tetranitro-1, 3, 5, 7-tetrazocine (HMX), Pentaerythritoltetranitrate (PETN), 2, 4, 6Trinitrophenylmethylnitramine (Tetryl) and 1, 3, 5-Trinitro-1, 3, 5-triazacyclohexane 
(RDX). As can be seen, TCA presents better sensitivity for explosives than TCAC. And among the testing explosives, TCA shows higher selectivity to DNT vapor than other explosives. The main reason might be attributed to two factors, one is the microstructures of the fluorescent films, the other is the explosives molecular structure and their saturated vapor pressure. The aromatic nitro explosives, such as TNT, DNT and Tetryl could form $\pi-\pi$ stacking with rigid backbone easily compared to PETN, HMX and RDX $[12,30]$. Meanwhile, the saturated vapor pressure of DNT (411 ppb) is much higher than TNT (9.15 ppb), PETN (0.0107 ppb), HMX (0.0000000237 ppb), Tetryl (0.00741 ppb) and RDX (0.00485 ppb) [31]. Moreover, TCA has much looser microstructure than TCAC, which benefit the diffusion of explosives. Thus, these synergistic effects of DNT molecular structure and its saturated vapor pressure resulted in the TCA films are more sensitive to DNT vapor than other explosives vapor.

\section{Figure 2}

Figure 2. Fluorescence quenching efficiency of TCA and TCAC exposed to DNT and TNT, HMX, PETN, Tetryl and RDX vapor.

Figure 3a demonstrates the fluorescence quenching efficiency of TCA exposed to TNT and DNT vapor as a function of exposed time. The TCA films are more sensitive to DNT vapor, after the TCA films upon exposure to DNT vapor for $30 \mathrm{~s}$, the fluorescence quenching efficiency could be about $90 \%$. However, the fluorescence quenching efficiency of TCA to TNT is only $13 \%$ after $30 \mathrm{~s}$, and $47 \%$ after $300 \mathrm{~s}$. It should be noted that the response of TCA to DNT was rather rapid. As can be seen from the inset pictures (I) of Figure 3a, exposing TCA films to DNT for $5 \mathrm{~s}$, the fluorescence was 
quenched obviously. After $30 \mathrm{~s}$, the fluorescence was nearly quenched completely. While for TNT, there was nearly no fluorescence quenching could be observed by naked eyes. Such rapid and selective detection of TCA to DNT vapor has reached the high standard for real-time field detection. Moreover, the TCA films can be used repetitively shown in Figure $3 \mathrm{~b}$. After being exposed to DNT vapor for $30 \mathrm{~s}$, the TCA films exhibit the same fluorescence quenching efficiency after each cycle, and the fluorescence intensity could be recovered when the DNT vapor was removed. For comparison, some fluorescence quenching data for DNT from different literatures are summarized in the Table 1.

\section{Figure 3}

Figure 3. (a) Fluorescence quenching efficiency of TCA exposed to TNT and DNT vapor as a function of exposed time. The inset: photos of TCA films exposed to DNT vapor in 0 s, $5 \mathrm{~s}, 10 \mathrm{~s}, 30 \mathrm{~s}$; photos of TCA films exposed to TNT vapor in 0 s, 30 s. (b) Fluorescent recovery cycles of TCA films: the blue solid arrows represent the quenching process and the green dot arrows represent the recovery process. The solid black squares ( $\square$ ) correspond to the initial fluorescence intensity of TCA films or the recovery fluorescence intensity of quenched TCA films washed by methanol. The solid red circles (๑) correspond to the fluorescence intensity of TCA films exposed to DNT vapor.

Table 1 Fluorescence quenching data for DNT vapor from different literature.

\section{Table 1}


We further performed the detection of DNT residual products using the filter paper, because workers inevitably contact with DNT in actual production, such as preparation and packaging of explosive devices, the leakage of explosives will adsorb on human clothes and skins [41]. So the real-time field detection is very necessary. Figure 4a shows a common filter paper was immersed in TCA solution and dried under vacuum. This filter paper exhibits a blue emission under the UV light at $365 \mathrm{~nm}$ (Figure 4b). Then a gloved finger was rubbed with DNT, visible DNT particles were all brushed off, and the gloved finger pressed on the filter paper for $10 \mathrm{~s}$. As we can see from Figure $4 \mathrm{c}$, the finger print of the gloved finger could be observed under the UV light at $365 \mathrm{~nm}$ by the naked eye. These images illustrate the utility of the fluorescent filter paper for real-time field and visualized detection of trace DNT residual products.

\section{Figure 4}

Figure 4. (a) Image of filter paper after immersed in TCA solution $\left(10^{-5} \mathrm{M}\right)$ under daylight; (b) Image of TCA filter paper under UV light at $365 \mathrm{~nm}$; (c) Image of TCA filter paper contacted with human thumb, which rubbed with DNT.

\section{Conclusion}

In conclusion, we designed and synthesized two fluorescent small molecules, TCAC and TCA, which have same rigid backbone and different sidechains. Their spin-coated films exhibit blue emission and were used as the fluorescent sensor for explosives vapor detection. In particular, TCA films display not only rapid response but also high selectivity and sensitivity to DNT vapor and the films can be used repetitively. Moreover, we illustrate the utility of the TCA filter paper for real-time field and visualized detection of trace DNT residual products. 


\section{Acknowledgements}

We are grateful for the financial support from National Science Foundation of China

(grant numbers 50973041, 21374037).

\section{References}

[1] H. Ma, L. Yao, P. Li, O. Ablikim, Y. Cheng, M. Zhang, Highly Sensitive and Selective Fluorometric/Electrochemical Dual-Channel Sensors for TNT and DNT Explosives, Chem. Eur. J. 20 (2014), 11655-11658.

[2] H. Sohn, R. M. Calhoun, M. J. Sailor, W. C. Trogler, Detection of TNT and picric acid on surfaces and in seawater by using photoluminescent polysiloles, Angew.Chem. Int. Ed. 40 (2001), 2104-2105.

[3] H. Ma, F. Li, P. Li, H. Wang, M. Zhang, G. Zhang, M. Baumgarten, K. Müllen, A Dendrimer-Based Electropolymerized Microporous Film: Multifunctional, Reversible, and Highly Sensitive Fluorescent Probe, Adv. Funct. Mater. 26 (2016), 2025-2031.

[4] K. Håkansson, R. V. Coorey, R. A. Zubarev, V. L. Talrose, P. Håkansson, Low-mass ions observed in plasma desorption mass spectrometry of high explosives, J. Mass Spectrom. 35 (2000), 337-346.

[5] A. S. Chajistamatiou, E. B. Bakeas, A rapid method for the identification of nitrocellulose in high explosives and smokeless powders using GC-EI-MS, Talanta 151 (2016), 192-201.

[6] R. Luggar, M. Farquharson, J. Horrocks, R. Lacey, Multivariate analysis of statistically poor EDXRD spectra for the detection of concealed explosives, X-Ray Spectrom. 27 (1998), 87-94.

[7] D. S. Moore, Instrumentation for trace detection of high explosives, Rev. Sci. Instrum. 75 (2004), 2499-2512.

[8] A. K. M. Jamil, A. Sivanesan, E. L. Izake, G. A. Ayoko, P. M. Fredericks, Molecular recognition of 2,4,6-trinitrotoluene by 6-aminohexanethiol and surface-enhanced Raman scattering sensor, Sens. Actuators B: Chem. 221 (2015), 273-280.

[9] J. M. Sylvia, J. A. Janni, J. Klein, K. M. Spencer, Surface-enhanced Raman detection of 2, 4-dinitrotoluene impurity vapor as a marker to locate landmines, Anal. Chem. 72 (2000), 5834-5840.

[10] E. S. Forzani, D. Lu, M. J. Leright, A. D. Aguilar, F. Tsow, R. A. Iglesias, Q. Zhang, J. $\mathrm{Lu}, \mathrm{J}$. Li, N. Tao, A hybrid electrochemical-colorimetric sensing platform for detection of explosives, J. Am. Chem. Soc. 131 (2009), 1390-1391.

[11] J. Mbah, K. Moorer, L. Pacheco-Londono, S. Hernandez-Rivera, G. Cruz, Zero valent silver-based electrode for detection of 2,4,-dinitrotoluene in aqueous media, Electrochimica Acta, 88 (2013), 832-838.

[12] X. Sun, Y. Wang, Y. Lei, Fluorescence based explosive detection: from mechanisms to sensory materials, Fluorescence based explosive detection: from mechanisms to sensory materials, Chem. Soc. Rev. 44 (2015), 8019-8061.

[13] S. Rochat, T. M. Swager, Conjugated amplifying polymers for optical sensing applications, ACS Appl. Mater. Interfaces 5 (2013), 4488-4502.

[14] Z. Hu, B. J. Deibert, J. Li, Luminescent metal-organic frameworks for chemical sensing and explosive detection, Chem. Soc. Rev. 43 (2014), 5815-5840. 
[15] A. Yildirim, H. Acar, T. S. Erkal, M. Bayindir, M. O. Guler, Template-directed synthesis of silica nanotubes for explosive detection, ACS Appl. Mater. Interfaces 3 (2011), 41594164.

[16] R. Hu, N. L. Leung, B. Z. Tang, AIE macromolecules: syntheses, structures and functionalities, Chem. Soc. Rev. 43 (2014), 4494-4562.

[17] D. Li, Y. Zhang, Z. Fan, J. Yu, AIE luminogen-functionalised mesoporous nanomaterials for efficient detection of volatile gases, Chem. Commun. 51 (2015), 13830-13833.

[18] F. Akhgari, H. Fattahi, Y. M. Oskoei, Recent advances in nanomaterial-based sensors for detection of trace nitroaromatic explosives, Sens. Actuators B: Chem. 221 (2015), 867878.

[19] J. -S. Yang, T. M. Swager, Fluorescent Porous Polymer Films as TNT Chemosensors: Electronic and Structural Effects, J. Am. Chem. Soc. 120 (1998), 11864-11873.

[20] S. W. Thomas III, G. D. Joly, T. M. Swager, Chemical Sensors Based on Amplifying Fluorescent Conjugated Polymers, Chem. Rev. 107 (2007), 1339-1386.

[21] J. -S. Yang, T. M. Swager, Porous Shape Persistent Fluorescent Polymer Films: An Approach to TNT Sensory Materials, J. Am. Chem. Soc. 120 (1998), 5321-5322.

[22] G. Shi, Y. Qu, Y. Zhai, Y. Liu, Z. Sun, J. Yang, L. Jin, \{MSU/PDDA $\}_{n}$ LBL assembled modified sensor for electrochemical detection of ultratrace explosive nitroaromatic compounds, Electrochem. Commun. 9 (2007) 1719-1724.

[23] D. Nie, Z. Han, Y. Yu, G. Shi, Composites of multiwalled carbon nanotubes/polyethyleneimine (MWCNTs/PEI) and molecularly imprinted polymers for dinitrotoluene recognition, Sens. Actuators B: Chem. 224 (2016), 584-591.

[24] W. J. Peveler, A. Roldan, N. Hollingsworth, M. J. Porter, I. P. Parkin, Multichannel Detection and Differentiation of Explosives with a Quantum Dot Array, ACS Nano 10 (2016), 1139-1146.

[25] B. D. Piorek, S. J. Lee, M. Moskovits, C. D. Meinhart, Free-Surface Microfluidics/Surface-Enhanced Raman Spectroscopy for Real-Time Trace Vapor Detection of Explosives, Anal. Chem. 84 (2012), 9700-9705.

[26] J. I. Steinfeld, J. Wormhoudt, Explosives detection: a challenge for physical chemistry, Annu. Rev. Phys. Chem. 49 (1998), 203-232.

[27] M. A. Fierke, E. J. Olson, P. Buehlmann, A. Stein, Receptor-Based Detection of 2,4Dinitrotoluene Using Modified Three-Dimensionally Ordered Macroporous Carbon Electrodes, ACS Appl. Mater. Interfaces 4 (2012), 4731-4739.

[28] W. Chen, K. Hou, X. Xiong, Y. Jiang, W. Zhao, L. Hua, P. Chen, Y. Xie, Z. Wang, H. Li, Non-contact halogen lamp heating assisted LTP ionization miniature rectilinear ion trap: a platform for rapid, on-site explosives analysis, Analyst 138 (2013), 5068-5073.

[29] H. Nie, G. Sun, M. Zhang, M. Baumgarten, K. Müllen, Fluorescent conjugated polycarbazoles for explosives detection: Side chain effects on TNT sensor sensitivity, J. Mater. Chem. 22 (2012), 2129-2132.

[30] P. Vishnoi, M. G. Walawalkar, S. Sen, A. Datta, G. N. Patwari, R. Murugavel, Selective fluorescence sensing of polynitroaromatic explosives using triaminophenylbenzene scaffolds, Phys. Chem. Chem. Phys. 16 (2014), 10651-10658.

[31] R. G. Ewing, M. J. Waltman, D. A. Atkinson, J. W. Grate, P. J. Hotchkiss, The vapor pressures of explosives, TrAC Trends Anal. Chem. 42 (2013), 35-48.

[32] H. Zhou, Q. Ye, W. T. Neo, J. Song, H. Yan, Y. Zong, B. Z. Tang, T. S. A. Hor and J. Xu, Electrospun aggregation-induced emission active POSS-based porous copolymer films for detection of explosives, Chem. Commun. 50 (2014) 13785-13788.

[33] D. H. Wang, Y. Z. Cui, F. R. Tao, Q. F. Niu, T. D. Li, H. Xu, A novel film of conjugated polymer grafted onto gelatin for detecting nitroaromatics vapor with excellent inhibiting photobleaching, Sens. Actuators B: Chem. 225 (2016), 319-326. 
[34] A. Nguyen, C. M. Gonzalez, R. Sinelnikov, W. Newman, S. Sun, R. Lockwood, J. G. C. Veinot, A. Meldrum, Detection of nitroaromatics in the solid, solution, and vapor phases using silicon quantum dot sensors, Nanotechnology 27 (2016), 1-12.

[35] W. Xue, Y. Zhang, J. J. Duan, D. Liu, Y. W. Ma, N. Shi, S. F. Chen, L. H. Xie, Y. Qian , W. Huang, A highly sensitive fluorescent sensor based on small molecules doped in electrospun nanofibers: detection of explosives as well as color modulation, J. Mater. Chem. C 3 (2015), 8193-8199.

[36] J. Peng, K. Q. Ye, J. B. Sun, Y. Zhan, J. H. Jia, P. C. Xue, G. H. Zhang, Z. Q. Zhang, R. $\mathrm{Lu}$, Branched benzothiadiazole-cored oligomers with terminal carbazoles: Synthesis and fluorescence probing nitroaromatics, Dyes Pigments 116 (2015), 36-45.

[37] L. Guo, B. Zu, Z. Yang, H. Cao, X. Zheng, X. Dou, APTS and rGO co-functionalized pyrenated fluorescent nanonets for representative vapor phase nitroaromatic explosive detection, Nanoscale 6 (2014), 1467-1473.

[38] P. Beyazkilic, A. Yildirim, M. Bayindir, Formation of Pyrene Excimers in Mesoporous Ormosil Thin Films for Visual Detection of Nitro-explosives, ACS Appl. Mater. Interfaces 6 (2014), 4997-5004.

[39] K. R. Ghosh, S. K. Saha, Z. Y. Wang, Ultra-sensitive detection of explosives in solution and film as well as the development of thicker film effectiveness by tetraphenylethene moiety in AIE active fluorescent conjugated polymer, Polym. Chem. 5 (2014), 56385643.

[40] S. Shanmugaraju, H. Jadhav, R. Karthik, P. S. Mukherjee, Electron rich supramolecular polymers as fluorescent sensors for nitroaromatics, RSC Adv. 3 (2013), 4940-4950.

[41] K. K. Kartha, S. S. Babu, S. Srinivasan, A. Ajayaghosh, Attogram sensing of trinitrotoluene with a self-assembled molecular gelator, J. Am. Chem. Soc. 134 (2012), 4834-4841. 
Table 1 Fluorescence quenching data for DNT vapor from different literature .

\begin{tabular}{|c|c|c|c|}
\hline $\begin{array}{c}\text { Sensing material } \\
\text { (different explosives) }\end{array}$ & \multicolumn{2}{|c|}{$\begin{array}{l}\text { Fluorescence Quenching } \\
\text { efficiency (exposure time) }\end{array}$} & Reference \\
\hline TCA & $60 \%(5 s)$ & $90 \%(30 \mathrm{~s})$ & This work \\
\hline MSNF film & $62 \%(10 s)$ & $74 \%(30 s)$ & [17] \\
\hline F4 & $52 \%(30 s)$ & $79 \%(90 \mathrm{~s})$ & {$[32]$} \\
\hline Gel-P(DNT) & $60 \%(50 s)$ & $100 \%(300 \mathrm{~s})$ & {$[33]$} \\
\hline Si-QDs(DNT) & $70 \%(30 s)$ & $\sim$ & [34] \\
\hline PEO/MePyCz (DNT) & $24 \%(300 \mathrm{~s})$ & $\begin{array}{l}73.2 \%(7200 \\
\text { s) }\end{array}$ & {$[35]$} \\
\hline oligomer 1(DNT) & $48 \%(60 \mathrm{~s})$ & $77 \%(600 \mathrm{~s})$ & [36] \\
\hline $\begin{array}{l}\text { PVP/pyrene/APTS/r } \\
\text { GO nanonets (DNT) }\end{array}$ & $\sim$ & $89 \%(540 \mathrm{~s})$ & [37] \\
\hline F2 films (DNT) & $39.2 \%(30 \mathrm{~s})$ & $88.2 \%(300 \mathrm{~s})$ & {$[38]$} \\
\hline P1 (DNT) & $48 \%(10 s)$ & $97 \%(300 \mathrm{~s})$ & [39] \\
\hline 3 (DNT) & $\sim$ & $\sim 69 \%(600 \mathrm{~s})$ & [40] \\
\hline
\end{tabular}




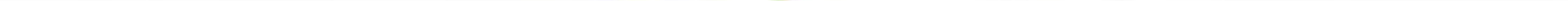


计, (0)

(10), $8(8)$

\section{TCA-DNT vapor}

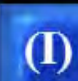



(ii)

(4)

9.6(0)

\section{(II)}

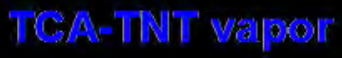

\section{0s $30 s$}

\& $81 .(0)((16)))$



(i).

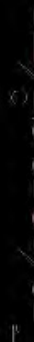

(x)
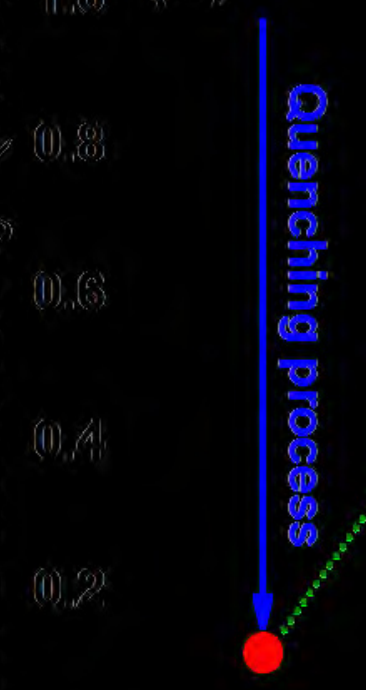

(i) (i)

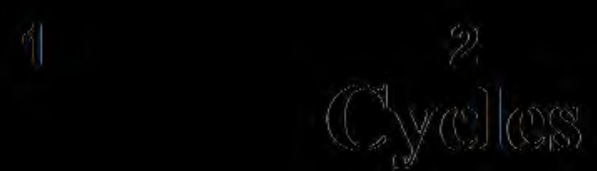


(a)

(b) 